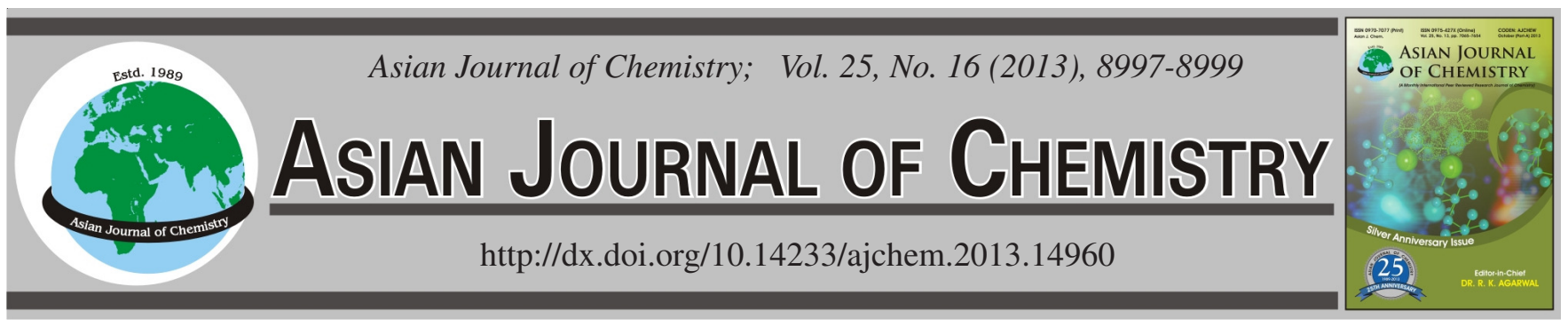

\title{
Microwave Synthesis of Chloroacetic Acid with Acetic Anhydride Catalyzing Chlorination of Acetic Acid
}

\author{
Li-Sheng Wang, Guo-Qiang Song, Ying Meng, Shou-Gao Li and Fu-XIAng Li*
}

Research Institute of Special Chemicals, Taiyuan University of Technology, Taiyuan 030024, Shanxi Province, P.R. China

*Corresponding author: Fax: +86 351 6111178; Tel: +86 351 6010550-3; E-mail: L63f64x@ 163.com

\begin{abstract}
In this paper, the chloroacetic acid has been synthesized with the acetic anhydride catalyzing chlorination of acetic acid by microwave irradiation. The volume fraction of acetic anhydride in acetic acid, reaction time, microwave power and reaction temperature have been investigated in the self-designed experimental device. The results showed that the optimum conditions were the volume fraction of acetic anhydride in acetic acid of $20 \%$, reaction time of $3.5 \mathrm{~h}$, microwave power of $300 \mathrm{~W}$, reaction temperature of $95^{\circ} \mathrm{C}$, the yield of chloroacetic acid was $94.31 \%$ and the selectivity was $93.01 \%$. Compared with ordinary heating, the selectivity and the reaction rate of using microwave irradiation were apparently improved.
\end{abstract}

Key Words: Microwave irradiation, Acetic anhydride, Chlorination, Acetic acid, Chloroacetic acid.

\section{INTRODUCTION}

Chloroacetic acid is an important fine chemical product, important raw material and intermediate in organic synthesis, which is widely used in medicines, pesticides, dyes, paint, paper chemicals, textile auxiliaries, surfactants, flavours, etc. With its downstream products about 100 species, it plays an important role in the national economy ${ }^{1}$.

N.le-blance discovered the chloroacetic acid at first; Hent sohel $^{2}$ found that acetic anhydride could accelerate the chlorination reaction for the first time in $1884 . \mathrm{Xue}^{3}$ used sulphur and acetic anhydride as the catalysts to do contrast experiments in 1999, drawing a conclusion that using acetic anhydride as catalyst, not only dosage is relatively less, but also the catalytic effect is better than the former.

At present the synthesis method of chloroacetic acid has been reported up to more than 10 species, but the industrialized methods are only acetic acid chlorination ${ }^{4}$, trichloroethylene hydrolysis ${ }^{5}$ and tetrachloroethane hydrolysis ${ }^{6}$. The acetic acid chlorination is currently the most common synthesis method, which is divided into sulphur catalyzing chlorination and acetic anhydride catalyzing chlorination of acetic acid according to different catalysts ${ }^{3,7}$.

The chlorination of acetic acid is widely applied at home and abroad. However, due to its traditional heating method, which results in slower reaction rate, lower reaction selectivity and poor product quality, higher consumption of raw materials and severe pollution, researching new production process has become the primary and necessary problem in our industry of chloroacetic acid. In this paper, based on modified frequency conversion of Midea microwave as the reaction heater, the acetic anhydride catalyzing was adopted to synthesize chloroacetic acid and investigate the influence of the volume fraction of acetic anhydride in acetic acid, reaction time, microwave power and reaction temperature in the self-designed experimental device, which aimed to improve the selectivity and reaction rate of the chlorination of acetic acid and get the optimum process conditions of microwave heating.

\section{EXPERIMENTAL}

\section{Main reaction:}

$\mathrm{CH}_{3} \mathrm{COOH}+\mathrm{Cl}_{2} \stackrel{\mathrm{CH}_{3} \mathrm{COOCOCH}_{3}}{\longrightarrow} \mathrm{ClCH}_{2} \mathrm{COOH}+\mathrm{HCl}$ By reaction:

$$
\begin{gathered}
\mathrm{ClCH}_{2} \mathrm{COOH}+\mathrm{Cl}_{2} \stackrel{\mathrm{CH}_{3} \mathrm{COOCOCH}_{3}}{\longrightarrow} \mathrm{Cl}_{2} \mathrm{CHCOOH}+\mathrm{HCl} \\
\mathrm{Cl}_{2} \mathrm{CHCOOH}+\mathrm{Cl}_{2} \stackrel{\mathrm{CH}_{3} \mathrm{COOCOCH}_{3}}{\longrightarrow} \mathrm{Cl}_{3} \mathrm{CCOOH}+\mathrm{HCl}
\end{gathered}
$$

Reaction mechanism can be seen in the references ${ }^{3,7}$.

Experimental reagents: Glacial acetic acid $\left(\mathrm{CH}_{3} \mathrm{COOH}\right)$, acetic anhydride $\left(\mathrm{CH}_{3} \mathrm{COOCOCH}\right)_{3}$, ethanol $\left(\mathrm{CH}_{3} \mathrm{CH}_{2} \mathrm{OH}\right)$, anhydrous calcium chloride $\left(\mathrm{CaCl}_{2}\right)$, ammonia water $(28 \%$ $\left.\mathrm{NH}_{3} \cdot \mathrm{H}_{2} \mathrm{O}\right)$, chloroform $\left(\mathrm{CHCl}_{3}\right)$, sodium hydroxide $(\mathrm{NaOH})$, ethylene glycol $\left(\mathrm{HOCH}_{2} \mathrm{CH}_{2} \mathrm{OH}\right)$, analytical reagent (AR)grade, all were purchased from TianYi Reagent Factory in Tianjin. Concentrated sulphuric acid $\left(98 \% \mathrm{H}_{2} \mathrm{SO}_{4}\right)$, AR, was from Chemical Insecticide Factory in Taiyuan. 
Experimental instruments: Infrared thermometer UT300A, Gas chromatograph GC-900 and Frequency conversion microwave heater (model EV923KF6-NA) were made by YaChen Electronic Technology Company in Shenzhen, HaiXin Chromatographic Instrument Company in Shanghai and Midea Microwave Electric Appliance Company in Guangdong, respectively.

Operating steps: $50 \mathrm{~mL}$ of glacial acetic acid and a certain amount of acetic anhydride were added into the self-designed reaction kettle with circle pipe. Then the slightly excess chlorine was bubbled in this reaction mixture. The microwave power was controlled and the water of different temperature was circulated in circle pipe to make reaction kept at a constant temperature. The tail gas was off after water cleaning and alkali cleaning. Products from chlorination reaction were analyzed with gas chromatograph after esterification.

Esterification reaction: $1 \mathrm{~mL}$ sample, $2 \mathrm{~mL}$ anhydrous ethanol and $1 \mathrm{~mL}$ concentrated sulphuric acid were added in a reaction tube, then put in boiled water for 5 min immediately. After cooled with the cooling water, $6 \mathrm{~mL}$ distilled water and $1.5 \mathrm{~mL}$ trichloromethane were added into the tube immediately, oscillated fiercely, standing for a moment. After oil and water phase were layered, the lowest oil phase for gas chromatography analysis was absorbed in a dry little bottle with a few anhydrous calcium chlorides.

\section{RESULTS AND DISCUSSION}

Influence of the volume fraction of acetic anhydride in acetic acid on chlorination: Microwave power was regulated at $300 \mathrm{~W}$ and the temperature of water in circle pipe was at $70{ }^{\circ} \mathrm{C}$ to make the reaction temperature be kept at $95^{\circ} \mathrm{C}$. The influence of different volume fraction $(5,10,15,20,25$ and $30 \%$ acetic anhydride in acetic acid) on chlorination was investigated.

As is shown in Table-1 (Fig. 1), when the volume fraction of acetic anhydride in acetic acid is less than $20 \%$, the chloroacetic acid yield and reaction selectivity were markedly increased with the volume fraction increasing. And at the volume fraction of $20 \%$, the reaction selectivity reached $93.01 \%$. However, the volume fraction continued to increase, once the volume fraction exceeds $20 \%$, the chloroacetic acid yield and reaction selectivity was improved significantly. Even, the reaction selectivity at the volume fraction of $30 \%$ was smaller than that at the volume fraction of $25 \%$. Considering the comprehensive factors of the cost of raw materials and energy consumption, the volume fraction of $20 \%$ acetic anhydride in acetic acid was the most suitable.

Influence of different microwave power on chlorination: The control of microwave power: the temperature of water in circle pipe was regulated into $100,90,80,60,50$ and $30^{\circ} \mathrm{C}$, respectively and the microwave power was correspondingly regulated at $0,100,300,500,700$ and $900 \mathrm{~W}$, to make reaction temperature stable at $100{ }^{\circ} \mathrm{C}$, which investigate the influence of different microwave power on chlorination.

Fig. 2 and Table- 2 shows the influence of different microwave power on the chloroacetic acid yield and reaction selectivity of chlorination. When the microwave power rises from $0-300 \mathrm{~W}$, the reaction selectivity get a constant increase.
TABLE-1

INFLUENCE OF THE VOLUME FRACTION OF ACETIC ANHYDRIDE IN ACETIC ACID ON CHLORINATION

\begin{tabular}{cccccc}
\hline $\begin{array}{c}\text { Volume fraction } \\
\text { of acetic } \\
\text { anhydride in } \\
\text { acetic acid (\%) }\end{array}$ & $\begin{array}{c}\text { Reaction } \\
\text { time (h) }\end{array}$ & $\begin{array}{c}\text { ACA } \\
(\%)\end{array}$ & $\begin{array}{c}\text { MCA } \\
(\%)\end{array}$ & $\begin{array}{c}\text { DCA } \\
(\%)\end{array}$ & $\begin{array}{c}\text { Selectivity } \\
(\text { mol \%) }\end{array}$ \\
\hline 5 & 3.5 & 28.24 & 70.43 & 1.33 & 60.78 \\
10 & 3.5 & 22.71 & 75.90 & 1.39 & 67.36 \\
15 & 3.5 & 19.09 & 79.22 & 1.69 & 71.68 \\
20 & 3.5 & 3.47 & 94.31 & 2.22 & 93.01 \\
25 & 3.5 & 2.27 & 95.30 & 2.43 & 94.68 \\
30 & 3.5 & 2.50 & 95.12 & 2.38 & 94.32 \\
\hline
\end{tabular}

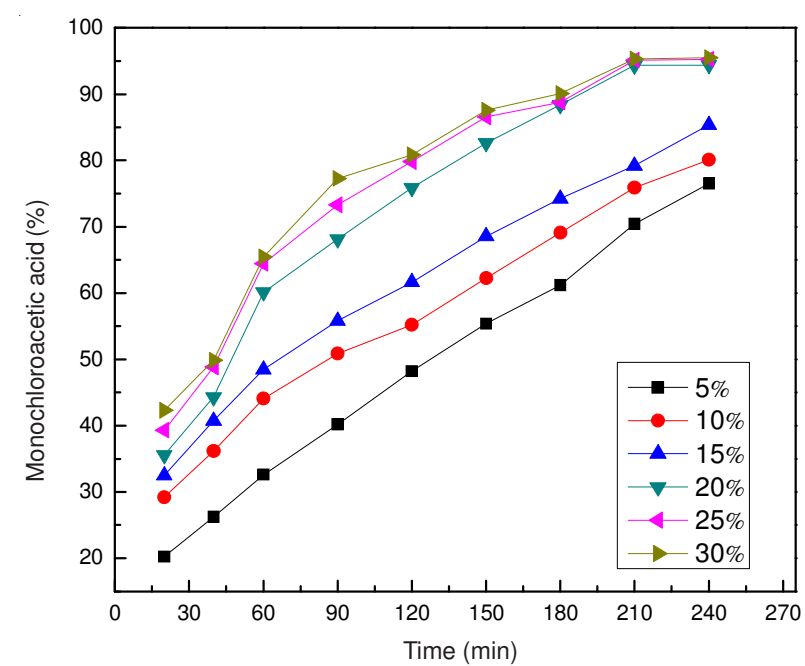

Fig. 1. Influence of the volume fraction of acetic anhydride in acetic acid on chlorination

\begin{tabular}{cccccc}
\multicolumn{7}{c}{ TABLE-2 } \\
\multicolumn{7}{c}{$\begin{array}{c}\text { INFLUENCE OF DIFFERENT MICROWAVE } \\
\text { POWER ON CHLORINATION }\end{array}$} \\
\hline Microware & $\begin{array}{c}\text { Reaction } \\
\text { Power (w) }\end{array}$ & $\begin{array}{c}\text { ACA } \\
\text { time }(\mathrm{h})\end{array}$ & $\begin{array}{c}\text { MCA } \\
(\%)\end{array}$ & $\begin{array}{c}\text { DCA } \\
(\%)\end{array}$ & $\begin{array}{c}\text { Selectivity } \\
(\%)\end{array}$ \\
\hline 0 & 3.5 & 25.02 & 73.45 & 1.53 & 64.44 \\
100 & 3.5 & 9.12 & 87.78 & 3.10 & 84.07 \\
300 & 3.5 & 5.25 & 91.20 & 3.55 & 89.35 \\
500 & 3.5 & 7.32 & 88.57 & 4.11 & 85.88 \\
700 & 3.5 & 8.61 & 86.51 & 4.88 & 83.47 \\
900 & 3.5 & 9.70 & 85.03 & 5.27 & 81.62 \\
\hline
\end{tabular}

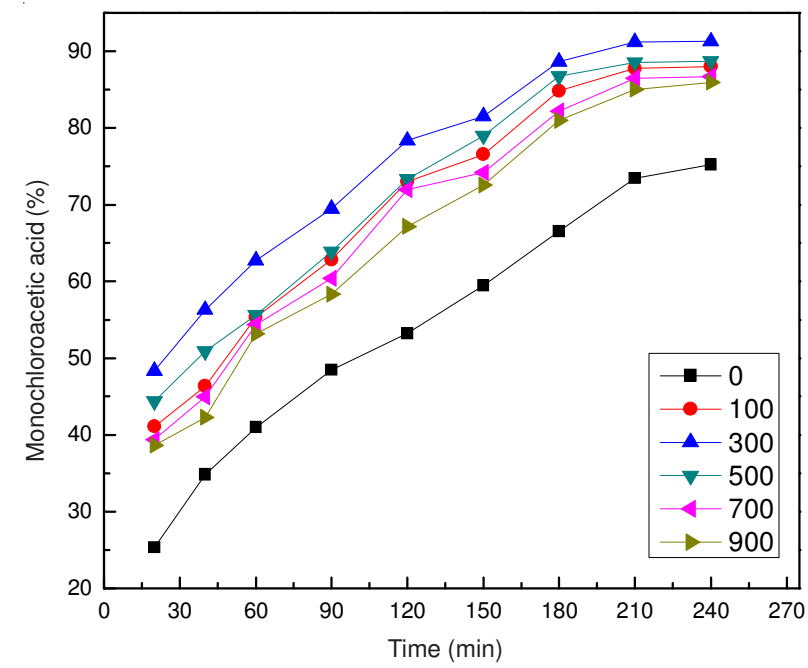

Fig. 2 Influence of different microwave power on chlorination 
At the microwave power of $300 \mathrm{~W}$, the $89 \%$ reaction selectivity is 1.39 times to $0 \mathrm{~W}$. However, the microwave power continues to increase, once the microwave power is more than $300 \mathrm{~W}$ and an opposite trend emerges. Thus the microwave power of $300 \mathrm{~W}$ is the optimum power of microwave-assisted to chlorination reaction. The chloroacetic acid yield and reaction selectivity can be improved by increasing microwave power, but very high microwave power results in opposite effect.

Fig. 2 indicates that all the reaction rates of chlorination with microwave are apparently faster than ordinary heating. In a word, the microwave accelerates the formation of chloroacetic acid and has a good catalytic effect on the chlorinated reaction.

Influence of the reaction temperature on chlorination: The control of reaction temperature: the temperature of water in circle pipe was regulated into 50, 60, 70, 80 and $90{ }^{\circ} \mathrm{C}$, respectively and microwave power was fixed at $300 \mathrm{~W}$ to make reaction temperature stable at $85,90,95,100$ and $105^{\circ} \mathrm{C}$, which investigate the influence of different reaction temperature on chlorination(volume fraction of $20 \%$ acetic anhydride in acetic acid).

The influence of different reaction temperature on the chloroacetic acid yield and reaction selectivity of chlorination are represented in Table-3 (Fig. 3). With increased reaction temperature, the chloroacetic acid yield and reaction selectivity of chlorination initially gradually increases and then decreases. At $95{ }^{\circ} \mathrm{C}$, the chloroacetic acid yield reaches $94.31 \%$ and the reaction selectivity reaches $93.01 \%$, which are the best chloroacetic acid yield and reaction selectivity.

\begin{tabular}{cccccc}
\multicolumn{7}{c}{ TABLE-3 } \\
\multicolumn{5}{c}{$\begin{array}{c}\text { INFLUENCE OF DIFFERENT REACTION } \\
\text { TEMPERATURE ON CHLORINATION }\end{array}$} \\
\hline $\begin{array}{c}\text { Reaction } \\
\text { temp. }\left({ }^{\circ} \mathrm{C}\right)\end{array}$ & $\begin{array}{c}\text { Reaction } \\
\text { time }(\mathrm{h})\end{array}$ & $\begin{array}{c}\text { ACA } \\
(\%)\end{array}$ & $\begin{array}{c}\text { MAC } \\
(\%)\end{array}$ & $\begin{array}{c}\text { DAC } \\
(\%)\end{array}$ & $\begin{array}{c}\text { Selectivity } \\
(\text { mol \%) }\end{array}$ \\
\hline 85 & 3.5 & 8.68 & 88.63 & 2.69 & 85.99 \\
90 & 3.5 & 7.36 & 89.61 & 3.03 & 86.64 \\
95 & 3.5 & 3.47 & 94.31 & 2.22 & 93.01 \\
100 & 3.5 & 4.75 & 91.20 & 4.05 & 89.72 \\
105 & 3.5 & 3.22 & 92.04 & 4.74 & 91.50 \\
\hline
\end{tabular}

Thus, a higher reaction temperature is favourable to the chloroacetic acid yield and reaction selectivity of the chlorinated reaction, but it is not the fact that the higher the reaction temperature is, the better the chloroacetic acid yield and reaction selectivity are.

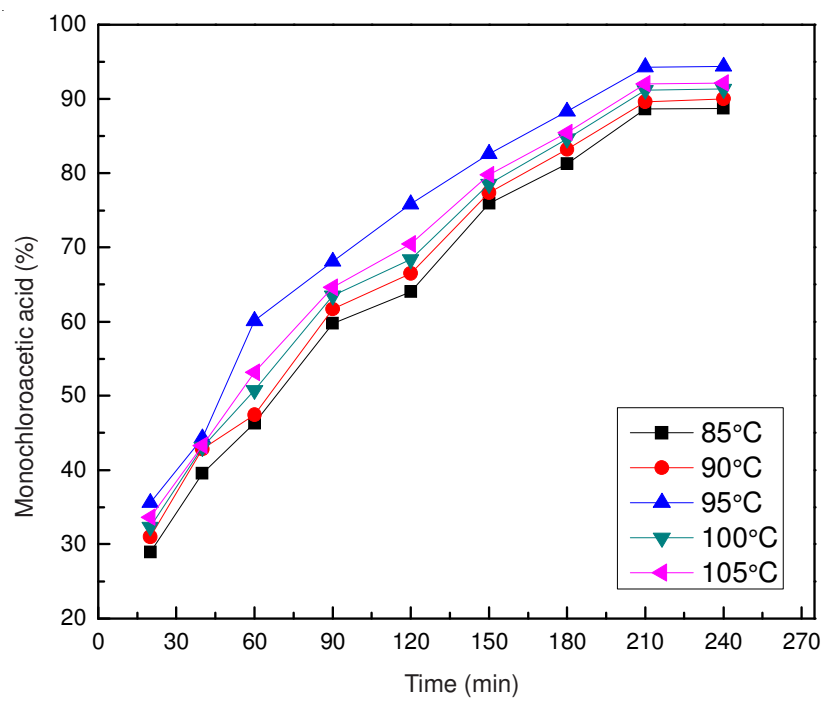

Fig. 3. Influence of different reaction temperature on chlorination

\section{Conclusion}

With the microwave irradiation, the chloroacetic acid was synthesized by the acetic anhydride chlorination of acetic acid. The microwave accelerates the formation of chloroacetic acid, cut the reaction time and has a good catalytic effect on the chlorinated reaction of acetic acid. The volume fraction of $20 \%$ acetic anhydride in acetic acid, reaction time of $3.5 \mathrm{~h}$, microwave power of $300 \mathrm{~W}$ and reaction temperature of $95^{\circ} \mathrm{C}$ are the relative optimum to the chlorination reaction. Under these conditions, the chloroacetic acid yield reaches $94.31 \%$ and the reaction selectivity reaches $93.01 \%$ and the reaction selectivity is 1.44 times than that with methods of the ordinary heating.

\section{REFERENCES}

1. Y. H. Li, J. Chem. Ind. Times, 17, 20 (2003).

2. L. Giuffre, E. Montoneri, E. Tempesti, V. Pozzi and F. Rossi, J. Chem. Ind., 63, 85 (1981).

3. J.W. Xue, Z. Wu and Z.P. Lv, J. Taiyuan Univ. Technol., issue no. 6, 651 (1999).

4. E.K. Morris and W.W. Bakka, US Patent 3152174 (1960).

5. Y. Correa and G. Dumas, Eur. Patent 4496 (1979).

6. Y. Teruo, S. Kazuo and K. Yusuke, JPN Patent 78680719 (1978).

7. X.Z. Zhang, F.X. Li, Z.P. Lv and J.W. Xue, J. Taiyuan Univ. Technol., issue no. 3, 315 (2004). 